\title{
SUPPLIER-TASK SCHEDULING FOR THE LOGISTIC SUPPORT REGARDING SUPPLY CHAIN MANAGEMENT BASED ON PRECEDENCE
}

\author{
DOI: 10.17261/Pressacademia.2018.987 \\ JMML- V.5-ISS.4-2018(2)-p.267-274
}

\section{Mehmet Karakoc}

Bilkav Education and Consultancy (OptiWisdom Consultancy, Education \& Software Inc.), Istanbul, Turkey. mehmetkarakoc@optiwisdom.com, ORCID ID: 0000-0003-4678-451X

Date Received: November 7, 2018

Date Accepted: December 18, 2018

\section{To cite this document}

Karakoc, M. (2018). Supplier-task scheduling for the logistic support regarding supply chain management based on precedence. Journal of Management, Marketing and Logistics (JMML), V.5(4), p.267-274.

Permanent link to this document: http://doi.org/10.17261/Pressacademia.2018.987

Copyright: Published by PressAcademia and limited licenced re-use rights only.

\section{ABSTRACT}

Purpose- In this study, an intelligent scheduling to efficiently make supplier-task assignments is proposed. As the logistic support regarding supply chain management, a scheduling program was developed to determine the suppliers to perform the existing tasks with the orders. Each of a number of suppliers performs a subset of all tasks with a certain order and it is aimed to perform all of them with the minimum cost. The limited number of tasks to be performed by each supplier is predetermined.

Methodology- The main contribution here is to model the problem so that each task can have a different precedence/weight. The multiobjective cost function hereby designed consists of two sub-costs: (1) the cost between source-task pair, and (2) the weights referring to the ordering precedence regarding the completion of the tasks to be performed by the same source. For the solution, a genetic algorithms based meta-heuristic was used.

Findings- To test the success of the algorithm, instances including different numbers of tasks and suppliers were created with various task weights. The results obtained by executing the developed algorithm on these instances are presented.

Conclusion- Moreover, it was observed that accurate and appropriate schedules could be generated within significant times.

Keywords: Assignment problem, scheduling, genetic algorithms, logistics, supply chain.

JEL Codes: C61, C63, C88

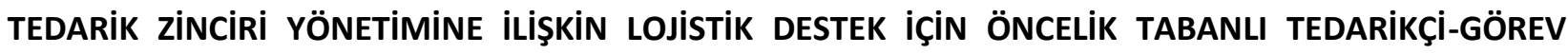 ÇiZELGELEME ${ }^{1}$}

\section{ÖZET}

Amaç- Bu çalışmada, tedarikçi-görev atamalarını verimli bir biçimde yapacak zeki bir planlama/çizelgeleme önerilmektedir. Tedarik zinciri yönetimine ilişkin lojistik destek programları kapsamında, mevcut görevlerin hangi tedarikçiler tarafından ve hangi sıralarla gerçekleştirileceğini belirleyecek bir çizelgeleme programı geliştirilmiştir. Bir dizi tedarikçiden her biri tüm görevlerin bir kısmını belirli bir sırada gerçekleştirir ve tüm görevlerin en az maliyetle gerçekleştirilmesi amaçlanır. Her tedarikçinin gerçekleştirebileceği sınırlı görev sayısı önceden belirlidir.

Yöntem- Çalışmanın temel katkısı, problemin her görevin farklı bir önceliği/ağırlığı olabilecek şekilde modellenmiş olmasıdır. Bu amaçla tasarlanan çok-hedefli maliyet fonksiyonu iki alt-maliyetten oluşmaktadır: (1) kaynak-görev ikilisi arasındaki maliyet ve (2) aynı kaynak tarafından gerçekleştirilecek görevlerin tamamlanmalarına ilişkin sıralama önceliğini ifade eden ağırlık değerleri. Çözüm için genetik algoritmalar tabanlı meta-sezgisel bir yöntem kullanıldı.

Bulgular- Algoritmanın başarısını test edebilmek için çeşitli görev ağırlıkları ile farklı sayılarda görevler ve tedarikçiler içeren örnekler oluşturuldu. Geliştirilen algoritma bu örnekler üzerinde işletilerek elde edilen sonuçlar sunulmuştur.

Sonuç- Doğru ve uygun çizelgelerin kayda değer sürelerde üretilebildiği gözlemlenmiştir.

Anahtar Kelimeler: Atama problemi, çizelgeleme, genetik algoritmalar, lojistik, tedarik zinciri.

JEL Kodları: C61, C63, C88

${ }^{1}$ Bu çalışma, 7. Ulusal Lojistik ve Tedarik Zinciri Kongresi'nde (ULTZK 2018) tam metin bildiri olarak sunulmuştur. 


\section{Giriş}

Organizasyonların ihtiyaçlarını çıkış noktasından varış noktasına kadar verimli bir biçimde ve en düşük maliyetle karşılamaları süreklilik için son derece önemlidir. Kaynakların yerinde ve zamanında sağlanabilmesi amacıyla, dağıtım, depolama, envanter girişi, etiketleme, gümrükleme, nakliye, paketleme, pazarlama, satın alma, sevkiyat, sipariş yönetimi, stok kontrolü, talep tahmini, üretim, yer seçimi vb. etkinliklerin başarı ile yerine getirilmesi gerekir. Bu nedenle de lojistik desteğe (geri hizmet) ihtiyaç duyulur. Lojistik sürecin işleyişi kapsamında, süreç içerisindeki hareketin planlanması, uygulanması, kontrol altında tutulması ve finanse edilmesi söz konusudur. Tüm sektörlerde, işin hangi düzey ve aşamada olduğu ile ilgili denetimler yapılır ve tedarikçilerden (başlangıç noktası - kaynak) son kullanıcılara (nihai tüketiciler) uzanan ve tedarik zinciri olarak adlandırılan içe ve/veya dışa odaklı bir akış mevcuttur.

Çizelgeleme problemi, bir dizi görevin yerine getirilmesi için kaynakların (derslikler, gözetmenler, öğrenciler vb.) zaman üzerinden tahsisi/dağıtımı olarak ifade edilebilir. Çizelgeleme, her çalışma alanı için söz konusu olan ve dağıtım, planlama, sıralama vb. gerektiren problemlerin çözümü kapsamında dikkate alınan bir uygulamadır: (i) ders ve derslik dağıtımlarının yapılması, (ii) ders/sınav programlarının hazırlanması ve (iii) tedarikçi-görev atamalarının yapılması gibi. Karmaşık ve zor bir problem olup, kâğıt üzerinde çözülmesi günler ve hatta haftalarca sürebilmektedir. Öte yandan, bu süreç bireylerden alınan geribildirimler ile yinelemeli bir biçimde iyileştirilmelidir.

Tedarik zinciri yönetimine ilişkin tüm etkinliklerde, araç, eğitmen, makine ve tedarikçi gibi kaynaklar ve ziyaret edilecek müşteri, verilecek ders, yapılacak iş ve sağlanacak ürün gibi görevler söz konusudur. Pek çok paydaş ve tarafın da yer aldığı bu etkinliklerin verimli bir biçimde gerçekleştirilebilmesi için araç-müşteri, eğitmen-ders, makine-iş ve tedarikçi-ürün gibi kaynak-görev ikilileri arasında atamaların yapılması gerekir. Bu işlem, sınırlı kaynakların görevlere en uygun şekilde tahsis edildiği planlamaları/çizelgeleri içermektedir. Bu problem, yöneylem araştırması alanına ilişkin bir gerçek-dünya problemi olup, literatürde atama problemi olarak yoğun bir biçimde çalışılmaktadır. Bir dizi kaynak ve bir dizi görev için toplam atama maliyetini en aza indirecek eşleşmelerle, her göreve tam olarak bir kaynak atayarak tüm görevlerin gerçekleştirilmesi amaçlanır.

Tek tedarikçinin gerçekleştirmesi gereken az sayıda görev söz konusu olduğunda, problem kâğıt üzerinde kolaylıkla çözülebilir. Çok sayıda görev söz konusu olduğunda ise çözüm uzun sürebilir. Öte yandan, çok tedarikçinin gerçekleştirmesi gereken çok sayıda görev söz konusu olduğunda, problemin kâğı üzerinde çözümü olanaksız olabilmekte, klasik yöntemlerle ise çok uzun sürebilmektedir. Bununla birlikte, her biri farklı önceliklere sahip olabilen çok sayıda görev için dikkate alınması gereken farklı durumlar da oluşur. Görev sayısının ve/veya tedarikçi sayısının artmasıyla, problemin karmaşıklığı (çözüm zamanı) üstel olarak artar. Bu nedenle de bu eniyileme (optimization) probleminin çözümü için bilgisayar bilimleri alanına ilişkin genetik algoritmalar (genetic algorithms - GA), tavlama benzetimi (simulated annealing) ve yasaklı arama (tabu search) gibi sezgisel yöntemlerden (heuristics) yararlanılarak zeki bilgisayar uygulamaları geliştirilebilir.

Bu çalışmada, tedarikçi-görev atamalarını verimli bir biçimde yapacak zeki bir planlama/çizelgeleme önerilmektedir. Tedarik zinciri yönetimine ilişkin lojistik destek programları kapsamında, mevcut görevlerin hangi tedarikçiler tarafından ve hangi sıralarla gerçekleştirileceğini belirleyecek bir çizelgeleme programı geliştirilmiştir. Bir dizi tedarikçiden her biri tüm görevlerin bir kısmını belirli bir sırada gerçekleştirir ve tüm görevlerin en az maliyetle gerçekleştirilmesi amaçlanır. Her tedarikçinin gerçekleştirebileceği sınırlı görev sayısı önceden belirlidir. Metnin geri kalan kısmı şu şekilde düzenlenmiştir. 2. Bölüm'de, yapılan alan yazını taraması sunulmuştur. 3. Bölüm'de, ele alınan problem ve geliştirilen model ayrıntılı olarak açıklanmıştır. Çözüm yöntemi ve örnek senaryolar 4. Bölüm'de verilmiş, elde edilen sonuçlar ise 5. Bölüm'de özetlenmiştir.

\section{LITERATÜR ARAŞTIRMASI}

Phillips vd. (2015), üniversite ders çizelgeleme (university course timetabling) kapsamında derslik atama problemini (classroom assignment problem) çalışmışlardır. Elen ve Çayıroğlu (2010), ders çizelgeleme problemini (course scheduling problem) çalışmışlar ve çözüm için GA kullanılmıştır. Öğrenci işleri otomasyonu kapsamında, yönetim, ders ve sınav olarak üç modül ele alınmıştır. Abbaszadeh vd. (2012), üniversite sınıf çizelgeleme problemini (university class scheduling problem) ele almışlar ve bir taklitçi algoritma (memetic algorithm) önerilmiştir. Fong vd. (2014) ise üniversite çizelgeleme problemini (university timetabling problem - sınav ve ders) çalışmışlar ve great deluge ve yapay arı kolonisi (artificial bee colony) algoritmalarının birleşiminden oluşan yeni bir melez yöntem önerilmiştir. Deneysel çalışmaları, bu yöntemin temel yapay arı kolonisi algoritmasından daha iyi kalitede çözümler ürettiğini göstermiştir. Chen ve Shih (2013), üniversite ders çizelgeleme problemini çalışmışlardır. Çözüm için parçacık sürüsü eniyilemesi (particle swarm optimization) uygulanmış ve çözüm kalitesini artırmak amacıyla bir takas sezgiselinden (interchange heuristic - yerel arama / local search) yararlanılmıştır. Deneysel çalışmaları, önerdikleri çözümün 
hocalara ve sınıflara ilişkin gereksinimleri karşılayan en uygun ders çizelgelerini üretebileceğini göstermiştir. Badoni vd. (2014) ise üniversite ders çizelgeleme probleminin çözümü için $G A$ ve yerel aramayı birleştiren yeni bir melez algoritma tanımlamışlardır. Algoritma, öğrencileri gruplandırma temelli olayları kullanır. Öğrencilerden oluşan nesne kümesi karşııklı ayrık öğrenci gruplarına ayrılır, öğrenci grupları için söz konusu olan ders anlatımları ve seminerler gibi olaylar zaman-dilimleri ve dersliklere atanır. Tüm keskin kısıtlar sağlanarak makul çözümler elde edilir ve bunu koruyarak esnek kısıtları eniyilemek amaçlanır.

Huang vd. (2012), TV-tabanlı etkileşimli öğrenme ortamında veri yayını (data broadcast) için uygun bir izleme modu (watching mode) tasarlamışlardır. Onlara göre, sayısal bir dersin uzun bir süre için sürekli olarak izlenmesinde, hem cihazların gücü hem de kullanıcı sabrı müsait öğrenme zamanını sınırlandırmaktadır. Öğrenicinin (learner), verilen süre içerisinde olabildiğince çok farklı derse erişebilmesinde (ders çizelgeleme söz konusu), izleme modunu eniyilemenin hesaplama maliyetini düşürmek amacıyla GA kullanılmıştır.

Ayob ve Malik (2011), zaman-dilimlerine zaten atanmış olan sınavları dikkate alarak, sınavları dersliklere atama problemini çalışmışlar ve yeni bir model önerilmiştir. Modelde, tek sınavın birden fazla dersliğe bölünmesi zorunlu olduğunda, bu sınava atanacak derslik sayısını en aza indirme (minimization) amaçlanmaktadır. Acar ve Şevkli (2013), öğretim üyelerinin ve öğrencilerin isteklerini dikkate alarak sınav çizelgeleme problemini (examination timetabling problem) çalışmışlardır. Çözüm için matematiksel bir model oluşturulmuş ve büyük problemler için bu modele dayalı sezgisel bir yöntem geliştirilmiştir. Alzaqebah ve Abdullah (2011) ise sınav çizelgeleme problemleri için arı algoritması (bees algorithm) kullanmışlardır. Deneysel çalışmalarında, algoritma üzerindeki değişikliklerle önerdikleri yaklaşımın, problemi çözmede umut verici sonuçlar ürettiği ve aynı problemler üzerinde test edildiğinde temel arı algoritmasından daha iyi başarım gösterdiği belirtilmiştir. Arogundade vd. (2010), sınav çizelgeleme problemi için yeni bir gerçek-dünya veri kümesi sunmuşlardır. Probleme ilişkin çözüm yöntemi kısıt hiyerarşisi kullanan $G A^{\prime}$ dır. Bu hiyerarşi, bireysel talepler veya kurumsal gereksinimleri birtakım ölçütlere göre ağılıklandırarak dâhil edebilir. Sınav veri kümelerinde her derslik için kapasite söz konusudur. Yeni amaç fonksiyonları her sınava atanmış hem zaman-dilimlerini hem de günleri dikkate almaktadır. Ayrıca, öğrenci grupları için sınavlar arasında boşluk oluşacak şekilde sınavlar belirli bir döneme yayılırlar. Jha (2014) ise sınav çizelgeleme problemini çözecek bir algoritma önermiş, probleme uygun çözüm için GA kullanmıştır.

Kayacı ve Yiğit (2012), tek makine çizelgeleme problemini çalışmışlar, erken veya geç tamamlanan iş sayısını en aza indirmek amacıyla bir model geliştirilmiştir. Sirkeci (2015), operasyonların verilen makine kümesi içerisindeki alternatiflerden birinde gerçekleşebiliyor olduğu (işlerin makinelere atanması) esnek atölye tipi çizelgeleme problemini ele almıştır. Çözüm için matematiksel modelleme (karışık tamsayı doğrusal programlama modeli), yerel arama ve tabu arama yöntemlerini kullanmıştır. Yerel arama, tabu arama ile daha iyi çözüm elde edilebilmesi için başlangıç çözüm olarak kullanılmıştır. Son işin tamamlanma zamanının en aza indirilmesi amacıyla, işlerin makinelerde sıralanması problemine yönelik çözüm yaklaşımları sunmuştur. Dilaver (2015) ise iş atölye çizelgeleme problemine ilişkin olarak, siparişlerin en kısa sürede tamamlanması için GA kullanan üç farklı çalışma incelemiştir. Yaptığı karşılaştırmalı incelemeyle, en iyi çözüme ulaşmada bu yöntemin şirketler için önemini vurgulamıştır. Kaya ve Engin'e (2009) göre, sabit iş çizelgeleme problemi ile ilgili olarak literatürde çok az çalışma yapıldığı bilinmektedir. Son yirmi yılda literatürde yapılan çalışmalar incelenmiş; operasyonel sabit iş çizelgeleme problemlerinin çözümünde, $G A$ ve tavlama benzetimi gibi meta-sezgisel yöntemlerin klasik yöntemlere göre daha iyi sonuçlar (en uygun ve/veya en uyguna yakın çözümler) verebileceği belirlenmiştir. Rinehart vd. (2003) ise çoklu-işlemci çizelgeleme problemi (multiprocessor scheduling problem) için GA'nın yeni bir türünü tanıtmışlardır. Yaklaşımlarında, sadece görevlerin (tasks) değil, kümelerin (clusters) de sıralanması söz konusu olup; algoritmalarında aramanın karmaşıklığını azaltmak için kümeleme/birleştirme (clustering/merging) eniyilemesi kullanılmıştır.

Ersöz ve Türker (2016), siparişe dayalı üretim gerçekleştiren işletmelerde siparişlerin dinamik çizelgeleme uygulaması için benzetim (simulation) paket programı ile oluşturulan modeller aracılı̆ııla iş yükleme öncelik stratejilerini denemişler ve en uygun olanı belirlenmeye çalışılmıştır. Karaöz (2014) ise üretim planlamasını kısa vadeli olarak yapan orta büyüklükte bir işletme için uzun vadeli üretim planlama ve çizelgeleme yapılmasını ele almıştır. İşletmenin sahip olduğu kömür madeni ocağında yaşanan sorunların çözülebilmesi amaçlanmıştır. Üretimsel kısıtları ve sahip olduğu cevherin özellikleri, tamsayılı matematiksel modellere uyarlanmıştır. Beş yıllık üretimde sağlayacağı toplam kârın en çoğa çıkarılması (maximization) ve çıkarılacak blokların sırasının belirlenmesi için planlama yapmıştır.

Çetin vd. (2008), ekip planlama problemi kapsamında, iki aşamasını oluşturan ekip eşleştirme ve ekip atama problemlerini çalışmışlardır. Havayollarında çalışan uçuş ekibi personelinin çizelgelenmesinde (üyelerin maliyetini en aza indirecek çözümleri 
üretmek amaçlanıyor), ekip eşleştirme sonuçları ekip atama için girdi olarak kullanılmış; çözüm küme bölme modeli biçiminde tamsayılı programlama ile gerçekleştirilmiştir. Kılıç ve Kaylan (2005), uçak çizelgeleme problemini çalışmışlar ve çözüm için metasezgisel bir yöntem olarak karınca kolonileri eniyilemesi kullanılmıştır. Her uçak için önceden belirli olan ve iniş yapılabilecek zaman-aralığını belirleyen alt ve üst sınırlar vardır ve tek veya çok pist kullanımında iniş ve kalkışların çizelgelenebilmesi söz konusudur. Aickelin ve Dowsland (2004), hemşire çizelgeleme problemini (nurse scheduling problem) çalışmışlar ve haftalık çizelgeler oluşturmak amacıyla GA kullanılmıştır. Yaldır ve Baysal (2012) ise sınav takvimi uygulamalarını ele almışlar ve ilgili uygulamanın geliştirilmesinde evrimsel hesaplama yöntemi olarak GA kullanılmıştır.

Çalışmanın temel katkısı, problemin her görevin farklı bir önceliği/ağırlığı olabilecek şekilde modellenmiş olmasıdır. Bu amaçla tasarlanan çok-hedefli maliyet fonksiyonu iki alt-maliyetten oluşmaktadır: (1) kaynak-görev ikilisi arasındaki maliyet ve (2) aynı kaynak tarafından gerçekleştirilecek görevlerin tamamlanmalarına ilişkin sıralama önceliğini ifade eden ağırlık değerleri. Bu kapsamda, tedarikçiler, gönderici, imalatçı, müşteri/personel, toptancı, üretici vb. paydaşlar, görevler ise cephane, donanım, insan, malzeme, teçhizat, tesis, yakıt ve yiyecek gibi mal/ürün ve/veya hizmet olabilir. Tüm görevleri tedarikçilere atama ve sıralama eniyilemesini yapacak bir uygulama geliştirilmiştir.

\section{VERI VE YÖNTEM}

Planlama/çizelgeleme genel bir problem olup, bir örneği rotalama problemi olabilir. Örneğin bir tedarikçinin gerçekleştireceği bir grup görev, bir aracın takip edeceği rota üzerindeki ziyaret edilecek bir dizi müşteri/konum olarak düşünülebilir. Bu karmaşık ve zor problemin çözümü, görevlerin atanacağı bir dizi tedarikçi için hem atama hem de sıralama gerektirir. Bir önceki çalışmamızda, tarım ürünleri ve gıdaların depolanması, taşınması ve dağıtılmasına yönelik tedarik zincirinin etkili bir biçimde yönetilebilmesi için söz konusu dağıtımın düşük maliyetle gerçekleştirilebileceği zeki bir rotalama yaklaşımı (Karakoç, 2017) önermiştik. Bu çalışmada ise bir önceki çalışmamızda ele aldığımız zeki rotalama yaklaşımı kapsamında kapasiteli araç rotalama probleminin çözümü için geliştirmiş olduğumuz yöntemi, ele aldığımız çizelgeleme probleminin çözümü için uyarladık. Bu amaçla mevcut model üzerinde yaptığımız değişiklikler Tablo 1'de verilmiştir. Diğer ayrıntılar için bir önceki çalışmamıza başvurulabilir.

Tablo 1: Geliştirilen Model

\begin{tabular}{|c|c|c|c|}
\hline \multicolumn{2}{|c|}{ Rotalama (Karakoç, 2017) } & \multicolumn{2}{|l|}{ Çizelgeleme } \\
\hline \multicolumn{2}{|c|}{ Araç } & \multicolumn{2}{|l|}{ Tedarikçi } \\
\hline \multicolumn{2}{|l|}{ Müşteri } & \multicolumn{2}{|l|}{ Görev } \\
\hline \multirow{3}{*}{ (her araç için) } & Rota & Görev sırası & \multirow{3}{*}{ (her tedarikçi için) } \\
\hline & Depodan hareket & Tamamlanacak ilk görev & \\
\hline & Depoya dönüş & Tamamlanacak son görev & \\
\hline \multicolumn{2}{|c|}{ Rota/arac sayısı } & \multicolumn{2}{|c|}{ Tedarikçi sayısı } \\
\hline \multicolumn{2}{|c|}{ İki konum arasındaki uzaklık simetriktir. } & \multicolumn{2}{|c|}{ Daha önemli görev daha önce atanır. } \\
\hline
\end{tabular}

Probleme ilişkin varsayımlar şunlardır:

Her göreve diğer görevlerden önce ve/veya sonra başlanır ve bu görev tamamlanır.

Tüm görevleri gerçekleştirebilecek yeterli sayıda tedarikçi mevcuttur.

Probleme ilişkin keskin kısıtlar ise şunlardır:

Her tedarikçi belirli bir sırada bir dizi görevi gerçekleştirir.

Her görev tam olarak bir tedarikçi tarafından ve sadece bir kez gerçekleştirilir.

Herhangi bir tedarikçinin gerçekleştirebileceği maksimum görev sayısı sınırlıdır.

Her tedarikçiye en uygun sırayla maksimum sayıda görev atanarak ve tüm görevlerin yerine getirilmesi amaçlanarak, gerekli tedarikçi sayısı en az ve toplam maliyet en düşük olacak şekilde, her tedarikçinin gerçekleştireceği bir grup görev ve sırası belirlenir. Ele alınacak senaryolar için yerine getirilmesi gereken altı görev ve bu görevleri gerçekleştirebilecek özdeş altı tedarikçi Tablo 2'de verilmiştir.

Tablo 2: Örnek Altı Görev ve Altı Tedarikçi Tanımı

\begin{tabular}{|l|l|l|l|l|l|}
\hline Görev & Tanım & $\mathbf{w}_{\mathbf{i}}$ & & Tedarikçi & Tanım \\
\hline
\end{tabular}




\begin{tabular}{|c|c|c|c|c|}
\hline $\mathrm{T}_{1}$ & 1. görevin tamamlanması & 2.00 & $\mathrm{~S}_{1}$ & 1. tedarikçi \\
\hline $\mathrm{T}_{2}$ & 2. görevin tamamlanması & 1.80 & $\mathrm{~S}_{2}$ & 2. tedarikçi \\
\hline$T_{3}$ & 3. görevin tamamlanması & 1.60 & $\mathrm{~S}_{3}$ & 3. tedarikçi \\
\hline $\mathrm{T}_{4}$ & 4. görevin tamamlanması & 1.40 & $\mathrm{~S}_{4}$ & 4. tedarikçi \\
\hline$T_{5}$ & 5. görevin tamamlanması & 1.20 & $\mathrm{~S}_{5}$ & 5. tedarikçi \\
\hline$T_{6}$ & 6. görevin tamamlanması & 1.00 & $\mathrm{~S}_{6}$ & 6. tedarikçi \\
\hline
\end{tabular}

Tablo 2'de, $T_{i}$ “i." görev ve $w_{i}$ bu görevin tamamlanma önceliğine ilişkin ağırlığı olup, $S_{k}$ ise "k." tedarikçidir. Ağırlığı "1"den fazla olan görevler, normalden daha yüksek önceliklere sahip olurlar. Örneğin en yüksek ağırlıklı ilk görevin önceliği son görevin önceliğinin iki katı olup, ilk olarak $T_{1}$ tamamlanmalıdır. İlgili bazı çözümler Tablo 3'te verilmiştir.

Tablo 3: Örnek Tanımlama için Bazı Çözümler

\begin{tabular}{|c|c|c|c|c|c|}
\hline Senaryo & $\mathbf{n}$ & $q$ & $\mathrm{~m}$ & Çözüm & Kromozom Gösterimi (aday çözümler) \\
\hline$(1)$ & 6 & 6 & 1 & $S_{1}: T_{1} T_{2} T_{3} T_{4} T_{5} T_{6}$ & " $\mathrm{T}_{0} \mathrm{~T}_{1} \mathrm{~T}_{2} \mathrm{~T}_{3} \mathrm{~T}_{4} \mathrm{~T}_{5} \mathrm{~T}_{6}$ " \\
\hline (2) & 6 & 2 & 3 & $\begin{array}{l}\mathrm{S}_{1}: \mathrm{T}_{1} \mathrm{~T}_{4} \\
\mathrm{~S}_{2}: \mathrm{T}_{2} \mathrm{~T}_{5} \\
\mathrm{~S}_{3}: \mathrm{T}_{3} \mathrm{~T}_{6} \\
\end{array}$ & " $T_{0} T_{1} T_{4} T_{0} T_{2} T_{5} T_{0} T_{3} T_{6} "$ \\
\hline (3) & 6 & 1 & 6 & $\begin{array}{l}S_{1}: T_{1} \\
S_{2}: T_{2} \\
S_{3}: T_{3} \\
S_{4}: T_{4} \\
S_{5}: T_{5} \\
S_{6}: T_{6}\end{array}$ & “ $T_{0} T_{1} T_{0} T_{2} T_{0} T_{3} T_{0} T_{4} T_{0} T_{5} T_{0} T_{6}$ " \\
\hline
\end{tabular}

Tablo 3'te, $n$ görev sayısı ve $q$ herhangi bir tedarikçinin gerçekleştirebileceği maksimum görev sayısı olup; $m$ ise tüm görevleri yerine getirmek için gerekli tedarikçi sayısıdır ve Denklem (1)'de verildiği gibi hesaplanabilir. Senaryo (1)'de, $S_{1}$ tüm görevleri “ $T_{1}$ $T_{2} T_{3} T_{4} T_{5} T_{6}$ " sırasıyla yerine getirmelidir. Örneğin üçüncü ve dördüncü görevlerin aynı ağırlığa sahip oldukları durumda, çözüm " $T_{1} T_{2} T_{4} T_{3} T_{5} T_{6}$ " olur. Senaryo (2)'de, her birinin ikişer görevi yerine getirmesi gerektiği üç tedarikçiye; senaryo (3)'te ise her birinin birer görevi yerine getirmesi gerektiği altı tedarikçiye ihtiyaç duyulur. Senaryo (2)'de, her tedarikçiye atanan ilk görev en önemli görevler, son görev ise en önemsiz görevlerdir. Aynı/benzer önceliğe sahip görevler için benzer atama ve sıralamalar yapılabilir. Senaryo (2) için olası 36 (3! × 3!) ve senaryo (3) için toplam 720 (6!) çözüm söz konusudur. Bununla birlikte, kromozom gösterimlerinde, tedarikçilere ilişkin sıralamaları birbirlerinden ayırabilmek için her birinin başına hiçbir etkisi olmayan boş görev $\left(T_{0}\right)$ dâhil edilir.

$$
\begin{aligned}
& m=n \div q(n \bmod q=0 \text { ise }) \\
& m=[n-(n \bmod q)] \div q+1(\text { diğer durumda })
\end{aligned}
$$

Aynı tedarikçiye atanmış ardışık $T_{i} T_{j}$ görev çifti için $T_{i}$ tamamlandıktan sonra $T_{j}$ gerçekleştirilir ve ara maliyeti $\left(c_{i j}\right)$ Denklem (2)'de verildiği gibi hesaplanır.

$$
c_{i j}=w_{j}-w_{i}
$$

Basit örnek bir senaryo Tablo 4'te, ilgili maliyet tablosu Tablo 5'te ve bu maliyet tablosu temel alınarak elde edilebilecek tüm olası çözümler ise Tablo 6'da verilmiştir.

Tablo 4: Üç Görev için Örnek Senaryo ( $q=3)$

\begin{tabular}{|l|l|l|l|}
\hline Görev & $\mathbf{T}_{\mathbf{1}}$ & $\mathbf{T}_{\mathbf{2}}$ & $\mathbf{T}_{\mathbf{3}}$ \\
\hline $\mathrm{W}_{\mathrm{i}}$ & 3 & 2 & 1 \\
\hline
\end{tabular}

Tablo 5: Örnek Senaryo için Maliyet Tablosu

\begin{tabular}{|l|l|l|l|l|l|l|l|l|}
\hline Görev Çifti & $\mathbf{T}_{\mathbf{1}} \mathbf{T}_{\mathbf{2}}$ & $\mathbf{T}_{\mathbf{1}} \mathbf{T}_{\mathbf{3}}$ & & $\mathbf{T}_{\mathbf{2}} \mathbf{T}_{\mathbf{1}}$ & $\mathbf{T}_{\mathbf{2}} \mathbf{T}_{\mathbf{3}}$ & & $\mathbf{T}_{\mathbf{3}} \mathbf{T}_{\mathbf{1}}$ & $\mathbf{T}_{\mathbf{3}} \mathbf{T}_{\mathbf{2}}$ \\
\cline { 1 - 2 } \cline { 5 - 7 } & -1 & -2 & & 1 & -1 & & 2 & 1 \\
\hline
\end{tabular}

Tablo 6: Örnek Senaryo için Tüm Olası Çözümler ( $m=1)$

\begin{tabular}{|l|l|l|l|l|}
\hline Alternatif & Çözüm & Ara Maliyetler & Toplam Maliyet & Sıfır Tabanlı Maliyet \\
\hline
\end{tabular}




\begin{tabular}{|l|l|l|l|l|}
\hline$(1)$ & $\mathrm{S}_{1}: \mathrm{T}_{1} \mathrm{~T}_{2} \mathrm{~T}_{3}$ & $-1+-1$ & -2 & 0 \\
\hline$(2)$ & $\mathrm{S}_{1}: \mathrm{T}_{1} \mathrm{~T}_{3} \mathrm{~T}_{2}$ & $-2+1$ & -1 & 1 \\
\hline \multicolumn{7}{|l|}{} \\
\hline$(3)$ & $\mathrm{S}_{1}: \mathrm{T}_{2} \mathrm{~T}_{1} \mathrm{~T}_{3}$ & $1+-2$ & -1 & 1 \\
\hline$(4)$ & $\mathrm{S}_{1}: \mathrm{T}_{2} \mathrm{~T}_{3} \mathrm{~T}_{1}$ & $-1+2$ & 1 & 3 \\
\hline \multicolumn{7}{|l|}{} \\
\hline$(5)$ & $\mathrm{S}_{1}: \mathrm{T}_{3} \mathrm{~T}_{1} \mathrm{~T}_{2}$ & $2+-1$ & 1 & 3 \\
\hline$(6)$ & $\mathrm{S}_{1}: \mathrm{T}_{3} \mathrm{~T}_{2} \mathrm{~T}_{1}$ & $1+1$ & 2 & 4 \\
\hline
\end{tabular}

Tablo 6'da, Tablo 4'teki senaryo için olası 6 (3!) çözüm söz konusudur ve birinci çözüm en düşük maliyetli olandır.

\section{4. ÇÖZÜM, BULGULAR VE TARTIŞMA}

Çözüm için bir önceki çalışmamızda geliştirmiş olduğumuz ve istatistiksel başarısını ortaya koyduğumuz GA tabanlı meta-sezgisel yöntem (Karakoç, 2017) kullanıldı. Bu yöntemin temel aldığı model, bu çalışmada geliştirdiğimiz modele genişletildi. Ayrıca algoritma, işletimi süresince nüfus içerisinde uygun-olmayan (kullanılamaz) herhangi bir aday çözüm olmayacak şekilde yapılandırıldı.

Çözüm için takip edilen akış şu adımlardan oluşmaktadır:

her tedarikçinin gerçekleştireceği bir grup görev ve sırası belirlenir

çözüm kümesi üretilir

görev listeleri oluşturulur

oluşturulan listeler geliştirilen kullanıcı arayüzleri üzerinden görsel olarak sunulur

elde edilen sonuçlar raporlama için dosyalara yazdırılır

Örnek bir senaryo Tablo 7'de, ilgili tüm olası çözümler ise Tablo 8'de verilmiştir.

Tablo 7: Altı Görev için Örnek Senaryo $(q=3)$

\begin{tabular}{|l|l|l|l|l|l|l|}
\hline Görev & $\mathbf{T}_{1}$ & $\mathbf{T}_{\mathbf{2}}$ & $\mathbf{T}_{\mathbf{3}}$ & $\mathbf{T}_{\mathbf{4}}$ & $\mathbf{T}_{\mathbf{5}}$ & $\mathbf{T}_{\mathbf{6}}$ \\
\hline $\mathrm{W}_{\mathrm{i}}$ & 1.0 & 2.5 & 1.5 & 2.0 & 1.0 & 3.0 \\
\hline
\end{tabular}

Tablo 8: Örnek Senaryo için Tüm Olası Çözümler $(m=2)$

\begin{tabular}{|l|l|l|l|l|l|l|l|}
\hline (1) & (2) & (3) & (4) & (5) & (6) & (7) & (8) \\
\hline $\mathrm{S}_{1}: \mathrm{T}_{6} \mathrm{~T}_{4} \mathrm{~T}_{1}$ & $\mathrm{~S}_{1}: \mathrm{T}_{6} \mathrm{~T}_{4} \mathrm{~T}_{5}$ & $\mathrm{~S}_{1}: \mathrm{T}_{6} \mathrm{~T}_{3} \mathrm{~T}_{1}$ & $\mathrm{~S}_{1}: \mathrm{T}_{6} \mathrm{~T}_{3} \mathrm{~T}_{5}$ & $\mathrm{~S}_{1}: \mathrm{T}_{2} \mathrm{~T}_{4} \mathrm{~T}_{1}$ & $\mathrm{~S}_{1}: \mathrm{T}_{2} \mathrm{~T}_{4} \mathrm{~T}_{5}$ & $\mathrm{~S}_{1}: \mathrm{T}_{2} \mathrm{~T}_{3} \mathrm{~T}_{1}$ & $\mathrm{~S}_{1}: T_{2} \mathrm{~T}_{3} T_{5}$ \\
$\mathrm{~S}_{2}: \mathrm{T}_{2} \mathrm{~T}_{3} \mathrm{~T}_{5}$ & $\mathrm{~S}_{2}: \mathrm{T}_{2} \mathrm{~T}_{3} \mathrm{~T}_{1}$ & $\mathrm{~S}_{2}: \mathrm{T}_{2} \mathrm{~T}_{4} \mathrm{~T}_{5}$ & $\mathrm{~S}_{2}: \mathrm{T}_{2} \mathrm{~T}_{4} \mathrm{~T}_{1}$ & $\mathrm{~S}_{2}: \mathrm{T}_{6} \mathrm{~T}_{3} \mathrm{~T}_{5}$ & $\mathrm{~S}_{2}: \mathrm{T}_{6} \mathrm{~T}_{3} \mathrm{~T}_{1}$ & $\mathrm{~S}_{2}: \mathrm{T}_{6} \mathrm{~T}_{4} \mathrm{~T}_{5}$ & $\mathrm{~S}_{2}: \mathrm{T}_{6} \mathrm{~T}_{4} \mathrm{~T}_{1}$ \\
\hline
\end{tabular}

Tablo 8'de, Tablo 7'deki senaryo için olası $8(2 ! \times 2 ! \times 2$ !) çözüm söz konusudur. Her çözümde, en yüksek ağırlıklı altıncı ve $i k i n c i$ görev tedarikçilere ilk atanan, en düşük ağırlıklı birinci ve beşinci görev ise tedarikçilere son atanan görevlerdir. Görüldüğü gibi, görev sayısının ve/veya tedarikçi sayısının artmasıyla, problem oldukça karmaşıklaşmaktadır. Önerilen çözüm, mevcut kaynağın verimli kullanımı için önemli çıktılar sağlayabilecektir.

Geliştirilen model, özellikle şu noktalarda oldukça esnektir. Örneğin belirli bir görevin yerine getirilmesinden kaçınılması için bu görevin ağırlığı sıfır olarak ayarlanabilir. Herhangi bir görev, uygun alt-görevlere bölünerek, aynı tedarikçi tarafından sıralı veya farklı tedarikçiler tarafından paralel olarak parça parça tamamlanabilir. Tüm süreç, veri tabanı oluşturularak ve ilgili bilgi yönetim sistemi geliştirilerek, bir web uygulaması veya mobil uygulama üzerinden takip edilebilir. Önceden belirli sınırlı görev sayısı ise (i) toplam iş yükü, (ii) kullanılabilir kaynak ve (iii) sınırlı tamamlanma zamanı dikkate alınarak, uygulama aracılığıyla geçmiş bilgiye bakılıp otomatik olarak belirlenebilir. Ayrıca, tamamlanan-kalan görevler, tedarikçi performansı ve verimlilik durumları ile ilgili analizler çıkartılabilir ve buna göre ileriye dönük düzenleme ve iyileştirmeler yapılabilir.

\section{SONUÇ VE ÖNERILER}


Bir önceki çalışmamızda, tarım ürünleri ve gıdaların depolanması, taşınması ve dağıtılmasına yönelik tedarik zincirinin etkili bir biçimde yönetilebilmesi için söz konusu dağııııın düşük maliyetle gerçekleştirilebileceği zeki bir rotalama yaklaşımı (Karakoç, 2017) önermiştik. Bu çalışmada ise bir önceki çalışmamızda ele aldığımız zeki rotalama yaklaşımı kapsamında kapasiteli araç rotalama probleminin çözümü için geliştirmiş olduğumuz yöntemi, ele aldığımız çizelgeleme probleminin çözümü için uyarladık. Bu amaçla mevcut model üzerinde değişiklikler yapıldı. Bir dizi tedarikçiden her biri tüm görevlerin bir kısmını belirli bir sırada gerçekleştirir ve tüm görevlerin en az maliyetle gerçekleştirilmesi amaçlanır. Her tedarikçinin gerçekleştirebileceği sınırlı görev sayısı önceden belirlidir. Çalışmanın temel katkısı, problemin her görevin farklı bir önceliği/ağırlığı olabilecek şekilde modellenmiş olmasıdır. Bu amaçla tasarlanan çok-hedefli maliyet fonksiyonu iki alt-maliyetten oluşmaktadır: (1) kaynak-görev ikilisi arasındaki maliyet ve (2) aynı kaynak tarafından gerçekleştirilecek görevlerin tamamlanmalarına ilişkin sıralama önceliğini ifade eden ağırlık değerleri.

Bu çalışmada, tedarikçi-görev atamalarını verimli bir biçimde yapacak zeki bir planlama/çizelgeleme önerildi. Tedarik zinciri yönetimine ilişkin lojistik destek programları kapsamında, mevcut görevlerin hangi tedarikçiler tarafından ve hangi sıralarla gerçekleştirileceğini belirleyecek bir çizelgeleme programı geliştirildi. Çözüm için GA tabanlı meta-sezgisel bir yöntem kullanıldı. Algoritmanın başarısını test edebilmek için çeşitli görev ağırlıkları ile farklı sayılarda görevler ve tedarikçiler içeren örnekler oluşturuldu. Geliştirilen algoritma bu örnekler üzerinde işletilerek elde edilen sonuçlar sunuldu. Doğru ve uygun çizelgelerin kayda değer sürelerde üretilebildiği gözlemlenmiştir. Düşük maliyetli çizelgelerin üretilebilmesiyle, özellikle kritik-zamanlı uygulamalarda görevlerin tamamlanmalarına yönelik yanıt zamanları azalabilecek; böylelikle, oluşabilecek kesintiler önlenerek tüketicilere daha güvenilir hizmet sağlanabilecektir. Geliştirilen uygulama, akışın sürekliliğini sağlamak için dinamik hâle getirilebilir. Model, özdeş olmayan tedarikçiler ve görevler için ek olarak tamamlanma zamanları da dikkate alınarak genişletilebilir.

\section{KAYNAKLAR}

Abbaszadeh, M., Saeedvand, S., Mayani, H. A. (2012). Solving university scheduling problem with a memetic algorithm. International Journal of Artificial Intelligence (IJ-AI), 1(2), pp.79-90.

Acar, M. F., Şevkli, M. (2013). Sınav çizelgelemesi için matematiksel model yaklaşımı. Verimlilik Dergisi, 1, ss.75-86.

Aickelin, U., Dowsland, K. A. (2004). An indirect genetic algorithm for a nurse scheduling problem. Computers \& Operations Research, 31(5), pp.761-778.

Alzaqebah, M., Abdullah, S. (2011). The Bees algorithm for examination timetabling problems. International Journal of Soft Computing and Engineering (IJSCE), 1(5), pp.105-110.

Arogundade, O. T., Akinwale, A. T., Aweda, O. M. (2010). A genetic algorithm approach for a real-world university examination timetabling problem. International Journal of Computer Applications (0975 - 8887), 12(5), pp.1-4.

Ayob, M., Malik, A. (2011). A new model for an examination-room assignment problem. IJCSNS International Journal of Computer Science and Network Security, 11(10), pp.187-190.

Badoni, R. P., Gupta, D. K., Mishra, P. (2014). A new hybrid algorithm for university course timetabling problem using events based on groupings of students. Computers \& Industrial Engineering, 78, pp.12-25.

Chen, R. M., Shih, H. F. (2013). Solving university course timetabling problems using constriction particle swarm optimization with local search. Algorithms, 6, pp.227-244.

Çetin, E. İ., Kuruüzüm, A., Irmak, S. (2008). Ekip çizelgeleme probleminin küme bölme modeli ile çözümü. Havacılık ve Uzay Teknolojileri Dergisi, 3(4), ss.47-54.

Dilaver, D. (2015). Genetik algoritmalar yardimiyla iş atölye çizelgelemesi üzerine bir çalişma. Dokuz Eylül Üniversitesi, Ekonometri Programı, Yüksek Lisans Tezi, İzmir.

Elen, A., Çayıroğlu, i. (2010). Solving of scheduling problem with heuristic optimization approach. Technology, 13(3), pp.159-172.

Ersöz, O. Ö., Türker, A. K. (2016). Üretim planlama ve kontrolün atölye yükü ile eşzamanli gerçekleştirilmesi. MANAS Sosyal Araştırmalar Dergisi, 5(5), ss.229-245.

Fong, C. W., Asmuni, H., McCollum, B., McMullan, P., Omatu, S. (2014). A new hybrid imperialist swarm-based optimization algorithm for university timetabling problems. Information Sciences, 283, pp.1-21. 
Huang, Y. M., Chen, C. C., Wang, D. C. (2012). Optimizing T-learning course scheduling based on genetic algorithm in benefit-oriented data broadcast environments. TOJET: The Turkish Online Journal of Educational Technology, 11(3), pp.255-266.

Jha, S. K. (2014). Exam timetabling problem using genetic algorithm. IJRET: International Journal of Research in Engineering and Technology, 03(05), pp.649-654.

Karakoç, M. (2017). Intelligent routing approach for the distributions regarding to the supply chain management of agricultural products and foods. Journal of Management, Marketing and Logistics (JMML), 4(2), pp.168-177. --- "Tarım Ürünleri ve Gıdaların Tedarik Zinciri Yönetimine iliş̧kin Dağııım İşlemleri için Zeki Bir Rotalama Yaklaşımı”, 6. Ulusal Lojistik ve Tedarik Zinciri Kongresi (ULTZK 2017), 17-19 Mayıs, Aska Lara Hotel, Antalya/Kundu.

Karaöz, B. (2014). Maden üretim planlamasi ve çizelgelemesi üzerine bir tam sayili programlama önerisi: kar maden örneği", Hacettepe Üniversitesi, Üretim Yönetimi ve Sayısal Yöntemler Programı, Yüksek Lisans Tezi, Ankara.

Kaya, S., Engin, O. (2009). Sabit iş çizelgeleme problemleri: literatür araştirmasi ve meta sezgisel yöntemler ile çözüm önerisi. iTÜ Dergisi Mühendislik, 8(1), ss.37-47.

Kayacı, M., Yiğit, V. (2012). Üretim çizelgeleme problemlerine bulanik yaklaşim. Atatürk Üniversitesi İktisadi ve İdari Bilimler Dergisi, 26(3-4), ss.287-296.

Kılıç, S., Kaylan, A. R. (2005). Uçak çizelgeleme probleminin karinca kolonileri optimizasyonu ile çözümü. Havacılık ve Uzay Teknolojileri Dergisi, 2(1), ss.87-95.

Phillips, A. E., Waterer, H., Ehrgott, M., Ryan, D. M. (2015). Integer programming methods for large-scale practical classroom assignment problems. Computers \& Operations Research, 53, pp.42-53.

Rinehart, M., Kianzad, V., Bhattacharyya, S. S. (2003). A modular genetic algorithm for scheduling task graphs. Technical Report UMIACS-TR2003-66, Institute for Advanced Computer Studies, University of Maryland at College Park, June.

Sirkeci, E. (2015). Esnek atölye tipi çizelgeleme problemi için çözüm yaklaşimlari: savunma sanayinde bir uygulama. Gazi Üniversitesi, Endüstri Mühendisliği Anabilim Dalı, Yüksek Lisans Tezi, Ankara.

Yaldır, A., Baysal, C. (2012). Evrimsel hesaplama tekniği kullanarak sinav takvimi otomasyon sistemi geliştirilmesi. Pamukkale Üniversitesi Mühendislik Bilimleri Dergisi, 18(2), ss.105-122. 